\title{
Batch grinding kinetics of Ethenzamide particles by fluidized-bed jet-milling
}

\author{
Tadashi Fukunaka $^{\text {a,* }}$, Boris Golman ${ }^{\text {b }}$, Kunio Shinohara ${ }^{\text {b }}$ \\ ${ }^{a}$ Banyu Pharmaceutical CO., LTD. 9-1, Kamimutsuna 3-Chome, Okazaki, Aichi 444-0858, Japan \\ ${ }^{b}$ Division of Chemical Process Engineering, Graduate School of Engineering, Hokkaido University, Nishi 8, Kita 13, Kita-ku, \\ Sapporo, Hokkaido 060-8628, Japan
}

\begin{abstract}
Ethenzamide solids as a representative active pharmaceutical ingredient (API) were batch-ground by means of a fluidized-bed jet-mill which is a relatively new equipment and promising for production in the pharmaceutical field. Thus, the characteristic grinding mechanism was investigated. As a result, the variation of the residual ratio with grinding time after milling was expressed simply by a mathematical model using only the first Kapur function, and it was consistent with experimental data satisfactorily. As the shape of the function was much different from that of inorganic compound and peculiar to API, a cubic function with respect to particle diameter was defined newly and well fitted to the experimental data. The function was also found to be affected by the operating parameters as the grinding gas pressure, the charge weight of raw material and the linear velocity at the grinding nozzle. According to the assessments of the breakage and the selection functions derived from the first Kapur function, it was found that the grinding mechanism of Ethenzamide particles was related with particle attrition mainly.

Keywords: Fluidized-bed jet-mill; Kinetics; Batch grinding; Mathematical model; Ethenzamide

* Corresponding author. Tel.: +81-564-57-1765; Fax: +81-564-57-1766.

E-mail address: tadashi_fukunaka@merck.com (T. Fukunaka).
\end{abstract}

\section{Introduction}

Since most of APIs developed in pharmaceutical industries have low solubility in water, production of fine particles by milling has been performed to increase the specific surface for the purpose of improving the solubility. Recently, the requirements for properties of milled particles, such as mean particle diameter and particle size distribution, are getting stricter and stricter.

However, the API milling process has not been developed so far on engineering approach, but on the past experiences mainly. In the pharmaceutical field, the fluidized-bed jet-mill is relatively new equipment comparing with the conventional equipments, such as a Jet-mill and a Pin-mill. One 
of the merits is less troubles like the deterioration of API's quality due to thermal effect (e.g. melt-back) and the shut-down due to compaction over the internal surfaces which is caused by the long operation, though the grinding mainly depends on inter-particle collision due to jet stream of gas (Fukunaka et al., 2003). The grinding characteristics of API have not been investigated enough.

Concerning the fluidized-bed jet-milling, a few studies have been performed in recent years. Heng et al. (2000) and Chan et al. (2002) worked qualitatively on the effect of the operating parameters on the particle size distribution and the particle shape after milling with lactose based on their experiments. Berthiaux and Dodds (1999) and Berthiaux et al. (1999) investigated batch and continuous grinding kinetics of alumina hydrate. However, the batch grinding kinetics of API, which is adhesive and agglomerative peculiar to pharmaceuticals, has not been investigated yet. Furthermore, the mathematical model of continuous operation which is important for optimization of pharmaceutical industrial grinding process should be based on the batch grinding one.

The objects of this paper are to analyze the grinding mechanism and to investigate the effect of the operating parameters on the breakage and the selection functions by batch grinding test with a representative model API, Ethenzamide, and fluidized-bed jet-mill.

\section{Theoretical considerations}

Based on Kapur (1970) model on batch grinding, Berthiaux and Dodds (1999) developed a simplified equation on the variation of oversize fraction, $R(x, t)$, with grinding time, $t$, as:

$$
R(x, t)=R(x, 0) \exp \left[\sum_{k=1}^{p} K^{(k)}(x) \frac{t^{k}}{k !}\right]
$$

Here the terms in the square bracket are called 'Kapur functions' including the complicated breakage and selection functions. The selection and the breakage functions mean the rate of breakage of unit mass fraction of particles of a certain size, and the distribution of mass fraction when a particle of a certain size is broken, respectively.

Thus, the ratio of oversize fraction at time, $t$, and initial one is defined as a residual ratio, $f(x, t)$, by equation (2). It characterizes the proportion of particles not to be subjected to the grinding action at $t$.

$$
f(x, t)=\frac{R(x, t)}{R(x, 0)}
$$


The Kapur functions must be determined by fitting to the particle size distributions. In the case of short grinding time, however, equation (1) can be reduced to the following simplest equation by substituting unit for $k$ :

$$
f(x, t)=\exp \left(K^{(1)}(x) t\right)
$$

Furthermore, the breakage and selection functions can be derived from the first Kapur function (Berthiaux et al., 1996) as:

$$
\begin{gathered}
S_{i}=-K^{(1)}\left(x_{i}\right) \\
B_{i j}=\frac{S_{i-1}-S_{i}}{S_{j}}
\end{gathered}
$$

where $j$ denotes the size class of particles to be ground and $i$ denotes the size class of particles to be produced by grinding $j$ size class of particles.

As it is considered to give a practical quantitative way of pharmaceutical grinding process, these equations based on equation (1) are assumed to be applied to the case of fine particles which have adherent and agglomerative properties as API.

\section{Materials and methods}

\subsection{Raw Material}

Ethenzamide particles $\left(\mathrm{C}_{9} \mathrm{H}_{11} \mathrm{NO}_{2}\right.$ : MW $165.19,1.25 \mathrm{~g} / \mathrm{cm}^{3}$, IWAKI SEIYAKU CO., LTD.) were used as a raw material which are needle shaped and highly cohesive. The SEM photograph and the particle size distribution are shown in Figs 1 and 2, respectively.

\subsection{Grinding equipment}

Fluidized-bed jet-mill (HOSOKAWA MICRON Corp. Counter Jet-mill 100 AFG) was used in the experiments, as schematically illustrated in Fig. 3. The grinding chamber consists of a cylindrical 
part with $97.4 \mathrm{~mm}$ inside diameter and a conical bottom, and the total volume is $950 \mathrm{~cm}^{3}$. Three grinding nozzles of 1.9 or $3.0 \mathrm{~mm}$ in opening diameter are located horizontally at 120 degree intervals in the bottom of ca. $162 \mathrm{~mm}$ from the center of the classifier rotor. The raw material was fed into the chamber from the top by a screw feeder, and is accelerated by nitrogen gas compressed up to $0.60 \mathrm{MPa}$ from the three nozzles to meet at the same point. The milled particles are classified by 50 ATP turbo-selector $(50 \mathrm{~mm}$ outside diameter, maximum rotor speed: $22000 \mathrm{rpm}$ which is located above the chamber. The classified fine particles leaving the grinding chamber are collected as a product in a bag-filter. The rejected coarse particles at the classifier are re-circulated in the chamber until they are ground into smaller size than a certain size to pass through the classifier rotor. The nitrogen passed through the filter is vented to atmosphere with a blower via HEPA filter.

\subsection{Batch grinding experiment}

Fig. 4 shows the schematic diagram of experimental setup. To perform batch grinding experiment, the material feed is cut off by installing a plug plate on the top of the chamber. A given weight of particles is put in the mill initially and the classifier is set to a maximum speed of rotation of $22000 \mathrm{rpm}$ to keep the particles inside the mill as much as possible. Although small amount of fine particles left the chamber during the experiment, it was unavoidable due to the scheme of equipment. Experiments were performed under the blower control by keeping the pressure inside the mill $-0.3 \mathrm{kPa}$ in any conditions. The grinding time was $60 \mathrm{sec}$ and the system was shut down at 10 sec intervals to take a portion of the milled sample collected at the bottom of the mill. Sampling was performed after $20 \mathrm{sec}$ to avoid scattering of data of particle size distribution. To minimize the influence of the sampling on the particle size distribution, the amount was 1-2 $\mathrm{g}$ in every time and the particles were well mixed prior to the sampling. The experiments were performed within practical range shown in Table 1 and the operating parameters are selected as the charge weight, the grinding gas pressure and the grinding nozzle diameter.

\subsection{Particle size distribution}

The particle size distribution was measured by means of a wet-type laser diffraction analyzer (MICROTRACK HRA Model\#6320-X100, NIKKISO Co., Ltd). The sample was set up by suspending particles in the $10 \mathrm{~mL}$ of Isopar-G (ExxonMobil Chemical) with 0.25 wt\% lecithin (Wako Pure Chemical Industries, Ltd.) as a dispersant and measured under deaggregation condition after sonication. 


\section{Results and discussion}

\subsection{Variation of residual ratio with time}

The oversize fraction of particles during milling, $R(x, t)$, is expressed by total mass balance with particle size distributions of samples collected inside and outside the mill as follows:

$$
R(x, t)=\frac{\left(W_{i n i}-W_{c l f}-W_{c l c}\right)}{W_{i n i}} R_{m i l l}(x, t)+\frac{W_{c l f}}{W_{i n i}} R_{c l f}(x)+\frac{W_{c l c}}{W_{i n i}} R_{c l c}(x)
$$

where $W$ is the weight of sample, subscripts " ini", " mill", "clf" and "clc" mean initial charge, sample in the mill, samples collected from the filter and the recovery pot of the bag-filter, respectively. In the present experiment, a part of coarse particles (subscript " $c l c$ ") to be retained inside, was discharged outside the mill with the product fine particles (subscript "clf") which were classified appropriately. In most of runs, as the weight fraction of $W_{c l c}$, which is presumed to affect the grinding process due to the existence inside the mill, was less than $10 \%$ of the charge weight, it is considered to cause little incovenience to investigate the process. Consequently, it is taken into account on the particle size distribution by equation (6). On the other hand, although the amount of the overflow is reduced by smaller charge weight, ranges of present experiment are considered as appropriate, because the grindability can not be evaluated in the case of the dilute particle concentration inside the mill.

Fig. 2 shows the variation of the oversize fraction with time for Run\#1. It is found that the distribution shifts to the left with time. Assuming that the grinding time is short, the variation of residual ratio with time for arbitrary particle size $x_{i}$ in the distribution is simplified using equation (3):

$$
f\left(x_{i}, t\right)=\exp \left(K^{(1)}\left(x_{i}\right) t\right)
$$

Therefore, the first Kapur function is obtained as the slope of the straight line by plotting $t$ vs $\ln \left\{f\left(x_{i}, t\right)\right\}$. As a typical result, Fig. 5 shows the variation of the residual ratio with time for Run\#1. In any fraction, the residual ratios linearly decrease with time to fit to equation (7). Since these trends were observed in all runs and the correlation coefficients, $\mathrm{R}^{2}$ values, were more than 0.8 , it 
was concluded that the influence of discharge of particles on the grinding process was comparatively small and the grinding time of present experiment was within the range to be applied to equation (7). Hereafter, the first Kapur function is thus obtained from the slope.

\subsection{Variation of first Kapur function with particle size}

Figs. 6 to 9 show the variations of the first Kapur function obtained in the previous section with particle size. As the y-axis shows the negative value of selection function as expressed by equation (4), it means that the bigger absolute value leads to higher probability to be ground. In this section, the first Kapur function is discussed as a selection function. The trends that the selection function was reversed in the range of 20 to $50 \mu \mathrm{m}$ due to two inflection points were observed. As the shape of the curve of first Kapur function is much different from the results using alumina hydrate (Berthiaux and Dodds, 1999) as shown in Fig. 6 (b) and the following equation, the grinding mechanism is considered to be peculiar to API. The detail is discussed later.

$$
K^{(1)}(x)=-A x^{\alpha} \frac{1}{1+\left(\frac{x}{\mu}\right)^{\beta}}
$$

Figs. 6 (a), 7 and 8 show the effect of the selection function with the charge weight under different grinding gas pressure of 0.3, 0.4 and $0.5 \mathrm{MPa}$ for $1.9 \mathrm{~mm}$-nozzle diameter, respectively. In case of lower pressure (0.3 MPa), larger charge weight leads to smaller selection function, because smaller charge leads to higher grinding energy per unit weight. In the case of higher pressure (0.4 and $0.5 \mathrm{MPa}$ ), larger charge weight leads to larger selection function, because the effect of the charge on the collision becomes effective due to plenty of unit energy.

Fig. 9 also shows the effects of the charge and the pressure using $3.0 \mathrm{~mm}$-nozzle on the selection function. As shown in Table 1, the grinding gas flow rate at $0.15 \mathrm{MPa}$ is almost the same as that at $0.5 \mathrm{MPa}$ using $1.9 \mathrm{~mm}$-nozzle. In the graph, it is found that although higher pressure and smaller charge lead to bigger selection function due to the same reason as shown in Fig. 6 (a). Furthermore, comparing Run\# 5, 8 and Run\#9, 10 at same gas flow rate, respectively, it is considered that the linear velocity much contributes to the increase in the selection function as compared with the gas flow rate.

The attempt to express the first Kapur function as a numerical formula was performed. Tanaka (1972) assumed that the selection function for jet-mill was in proportion to an exponent of particle size. In this paper, similarly to their power law dependence of selection function on particle size, a 
cubic equation by equation (9) is proposed considering both the graph shape and the physical meanings. It is considered that the selection function is affected by 3 primary factors as 1) collision energy which particles hold, 2) probability of existence of particles which can collide with and 3) particle size. These correspond to the cubic, quadratic and simple terms of equation (9), respectively. Tanaka (1972) considered that the rate constant was proportional to the probability of collisions of the particles injected into the jet and the kinetic energy of unit mass of particles hitting each other. Therefore, the cubic and the quadratic terms in equation (9) are considered to correspond to the collision energy and the probability of existence of particles, which seems to be proportional to the projected area which particles are sucked into the jet, respectively. For the simple term, according to Rittinger's law (1967), the surface energy (= specific surface area) which particles hold increases with progress of grinding, and is in inverse proportion to the particle size. That is to say, it is considered that the particle size corresponds to the surface energy, and the bigger it is, the easier it is ground.

Figs. 6 (a), 7, 8 and 9 show the results of calculation by equation (9). Since the calculated lines are fitted to the experimental results well, the assumption described above is considered to be appropriate. For all the runs, the coefficients and the constant in equation (9) obtained by fitting to experimental data are shown in Table 2 and $\mathrm{R}^{2}$ values are more than 0.9 .

$$
K^{(1)}(x)=a(\ln (x))^{3}+b(\ln (x))^{2}+c(\ln (x))+d
$$

\subsection{Bacth grinding model for API}

Substitution of equation (9) into equation (7) gives equation (10), which expresses the residual ratio with particle size, $x$, at time, $t$, after batch grinding. As a typical result, Fig. 10 depicts the experimental results of the residual ratio of Run\#1 and calculated lines obtained by equation (10). Since the calculated lines fitted to the experimental data well, the mathematical model for the batch grinding of API is found to be appropriate. Fig. 2 shows the calculated results of the variation of residual ratio with time obtained by equation (10). Although the calculated lines are almost fitted to the experimental data at each grinding time, for less than $4 \mu \mathrm{m}$ of particle size, the lines did not fit to the raw data due to the divergence of calculated values. This issue is caused by the functional form of equation (9) defining the first Kapur function as a logarithmic function with particle size. Considering the unique shape of the first Kapur function, as shown in Figs. 6 (a), 7, 8 and 9, equation (10) is applicable to a simple simulation of a residual ratio after batch grinding of API. 


$$
f(x, t)=\exp \left[\left\{a(\ln (x))^{3}+b(\ln (x))^{2}+c(\ln (x))+d\right\} t\right]
$$

\subsection{Assessment of Breakage Mechanism}

Approximating the grinding data by the first Kapur function, the breakage and the selection functions can be expressed by equations (4) and (5), respectively. As a typical result, the following breakage $B$ and selection $S$ matrices of Run\#1 are obtained by dividing the particle size range into 10 classes in the geometric progression, as written in Tables 3 and 4:

When $S$ is set as above, $B_{i j}$ is calculated by equation (5) as follows:

For example, at first, when $\mathrm{j}$ is given as one, $B_{21}$ is given as $\frac{S_{1}-S_{2}}{S_{1}}$. According to same procedure, $B_{31}$ to $B_{101}$ are calculated. Next, when $\mathrm{j}$ is given as two, $B_{32}$ is given as $\frac{S_{2}-S_{3}}{S_{2}}$. Then, the same iterations are performed up to $B_{109}$.

For the selection matrix, the selection function tends to increase with the particle size, because it is considered that bigger particles are easier to be ground corresponding to the first Kapur function. Only for the fractions from $i=3$ to 6 , however, the trends are reversed. Fig. 11 shows the mass distribution by focusing on the biggest particle class $(j=1)$ in the breakage matrix. In the graph, the fractions from $i=4$ to 6 are observed to be negative values. As it is unavoidable for them to be negative in the form of equation (5), they are assumed to be non-breakable fractions. It is found that the small particles up to $10.1 \mu \mathrm{m}$ ( $i=7$ to 10 ) and the big particles from 88 to $136 \mu \mathrm{m}(i=2)$ are milled selectively. As this trend is common to all runs, it is presumed that the grinding mechanism of Ethenzamide by fluidized-bed jet-milling mainly does not depend on the massive fracture that a big particle is divided into a few pieces, but on the attrition that small fragments are scraped off from the surface of a big particle, due to the physical property of organic compounds which have higher elastic properties than inorganic ones (Ragnarson and Sjogren, 1985).

\section{Conclusions}

The batch grinding kinetics and mechanism of Ethenzamide as a representative API by fluidized-bed jet-milling were investigated. As the result, the following findings were made: 
1) The variation of the residual ratio with the grinding time for each particle class after milling was expressed by equation (7) using only the first Kapur function. The shape of the curve of the function with particle size was much different from inorganic compounds, characteristic to API and fitted well to the cubic function expressed by equation (9).

2) The selection function derived from the first Kapur function was found to be affected by the operating parameters as the grinding gas pressure, the charge weight and the linear velocity at the grinding nozzle. Although, under low grinding pressure, the selection function tends to decrease with the increase in the charge weight, it was found to increase with the decrease in the charge under high pressure. At the same gas flow rate, the selection function increases with the linear gas velocity.

3) The mathematical model expressed by equation (10) for the batch grinding was consistent with experimental data satisfactorily.

4) According to the assessments of the breakage and selection functions, the grinding mechanism of Ethenzamide was supposed to depend mainly on particle attrition that small fragments are scraped off from the surface of a big particle due to the physical property of organic compounds which have higher elastic properties than inorganic ones. 


\section{Nomenclature}

$a, b, c, d \quad$ : Coefficients and constant in equation (9)

$\begin{array}{llr}A & : \text { Parameter in equation (8) } & \left(\mu \mathrm{m}^{-1} \mathrm{~s}^{-1}\right) \\ B & : \text { Breakage function as matrix } & (\mathrm{mm}) \\ d_{N} & : \text { Grinding nozzle diameter } & \\ f(x, t) & : \text { Residual ratio related to particle size } x \text { at time } t & \left(\mathrm{~s}^{-1}\right) \\ K^{(1)}\left(x_{i}\right) & : \text { 1st order Kapur function } & (\mathrm{MPa}) \\ k & : \text { Integer constant in equation (1) } \\ P & : \text { Grinding gas pressure } & \left(\mathrm{m}^{3} / \mathrm{min}\right) \\ Q & : \text { Grinding gas flow rate } \\ R(x, t) & : \text { Oversize fraction with respect to particle size } x \text { at time } t & \\ R(x) & : \text { Oversize fraction with respect to particle size } x & \left(\mathrm{~s}^{-1}\right) \\ S & : \text { Selection function as matrix } & (\mathrm{s}) \\ t & : \text { Grinding time } & (\mu \mathrm{m}) \\ x, x_{i} & : \text { Particle sizes } & (\mathrm{g}) \\ W & : \text { Weight of particles } \\ \alpha, \beta & : \text { Parameters in equation (8) } \\ \mu & : \text { Parameter in equation (8) } & (\mu \mathrm{m})\end{array}$

\section{$\langle$ Subscripts $>$}

clc : Coarse particles leaving the mill

clf : Fine particles leaving the mill

$i, j \quad:$ Indices relative to size intervals

ini : Initial charge of raw material

mill : Particles remaining in the mill 


\section{References}

Berthiaux, H. and Dodds, J., 1999. Modeling fine grinding in a fluidized bed opposed jet mill Part I: Batch grinding kinetics. Powder Technol., 106, 78-87.

Berthiaux, H., Chiron, C. and Dodds, J., 1999. Modeling fine grinding in a fluidized bed opposed jet mill Part II: Continuous grinding. Powder Technol., 106, 88-97.

Berthiaux, H., Varinot, C. and Dodds, J., 1996. Approximate calculation of breakage parameters from batch grinding tests. Chem. Eng. Sci., 51, 4509-4516.

Chan, L.W., Lee, C.C. and Heng, P.W.S., 2002. Ultrafine grinding using a fluidized bed opposed jet mill: Effects of feed load and rotational speed of classifier wheel on particle shape. Drug Dev. Ind. Pharm., 28, 939-947.

Fukunaka T and Tom, J. W., 2003. R\&D of milling technology in pharmaceutical industry. J. Soc. Powder Technol. Japan, 40, 655-663.

Heng, P.W.S., Chan, L.W. and Lee, C.C., 2000. Ultrafine grinding using a fluidized bed opposed jet mill: Effects of process parameters on the size distribution of milled particles. J. Pharm. Sci., 10, 445-451.

Kapur, P.C., 1970. Kinetics of batch grinding: Part B. An approximate solution to the grinding equation. Trans. Soc. Min. Eng. AIME, 247, 309-313.

Tanaka, T., 1972. Scale-up theory of jet mills on basis of comminution kinetics. Ind. Eng. Chem. Process Des. Develop., 11, 238-241.

Rittinger, Von PR. 1867. Lehrbuch der aufbereitungskunde in ihrer neusten entwicklung und ausbilding systematisch dargestellt. Ernst and Korn., Berlin.

Ragnarsson, G and Sjogren, J., 1985. Force-displacement measurements in tableting. J. Pharm.

Pharmacol., 37, 145-150. 


\section{Figure and table legends}

Fig.1 SEM photograph of Ethenzamide particles

Fig.2 Particle size distributions of raw material and inside samples for Run\#1

Fig.3 Schematic illustration of fluidized-bed jet-mill

Fig.4 Experimental setup for fluidized-bed jet-mill

Fig.5 Data fitting of residual ratio to grinding time by batch grinding

Fig.6 (a) Effect of charge weight on 1st Kapur function at $0.3 \mathrm{MPa}$ with $1.9 \mathrm{~mm}$-nozzle

Fig.6 (b) Variation of 1st Kapur function with particle size for Alumina hydtrate

Fig.7 Effect of charge weight on 1st Kapur function at $0.4 \mathrm{MPa}$ with 1.9mm-nozzle

Fig.8 Effect of charge weight on 1st Kapur function at $0.5 \mathrm{MPa}$ with $1.9 \mathrm{~mm}$-nozzle

Fig.9 Effects of charge weight and grinding pressure on 1st Kapur function with 3.0mm-nozzle

Fig.10 Fitting of batch grinding data by equation (10)

Fig.11 Mass distribution of fragments produced by breakage of particles of class 1 size

Table 1 Experimental condition by batch grinding

Table 2 Results of curve-fitting for 1st Kapur function

Table 3 Classification of particle size range

Table 4 Matrices of $S$ and $B$ calculated 


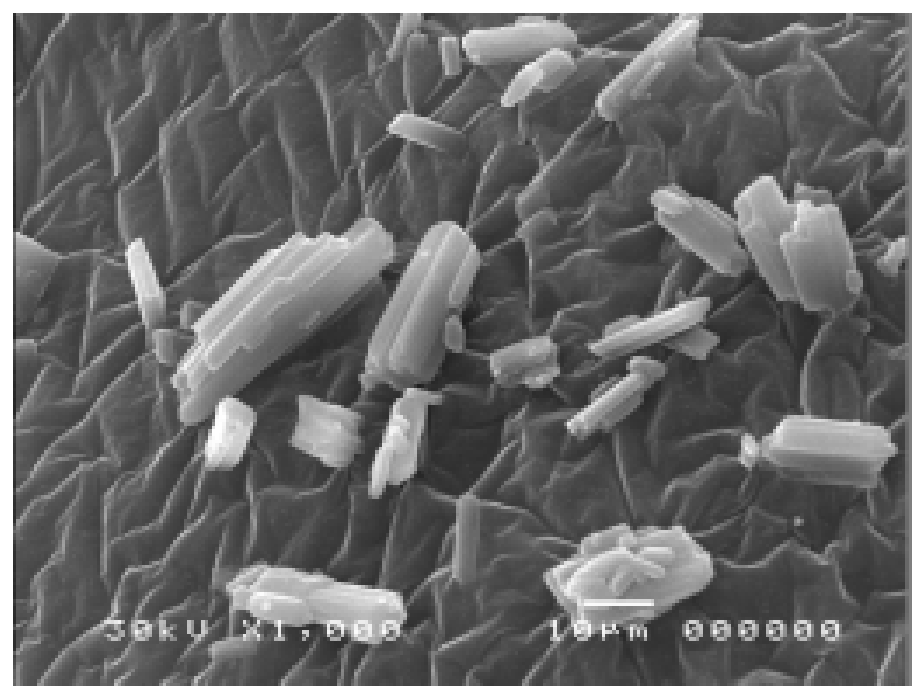

Fig. 1. SEM photograph of Ethenzamide particles 

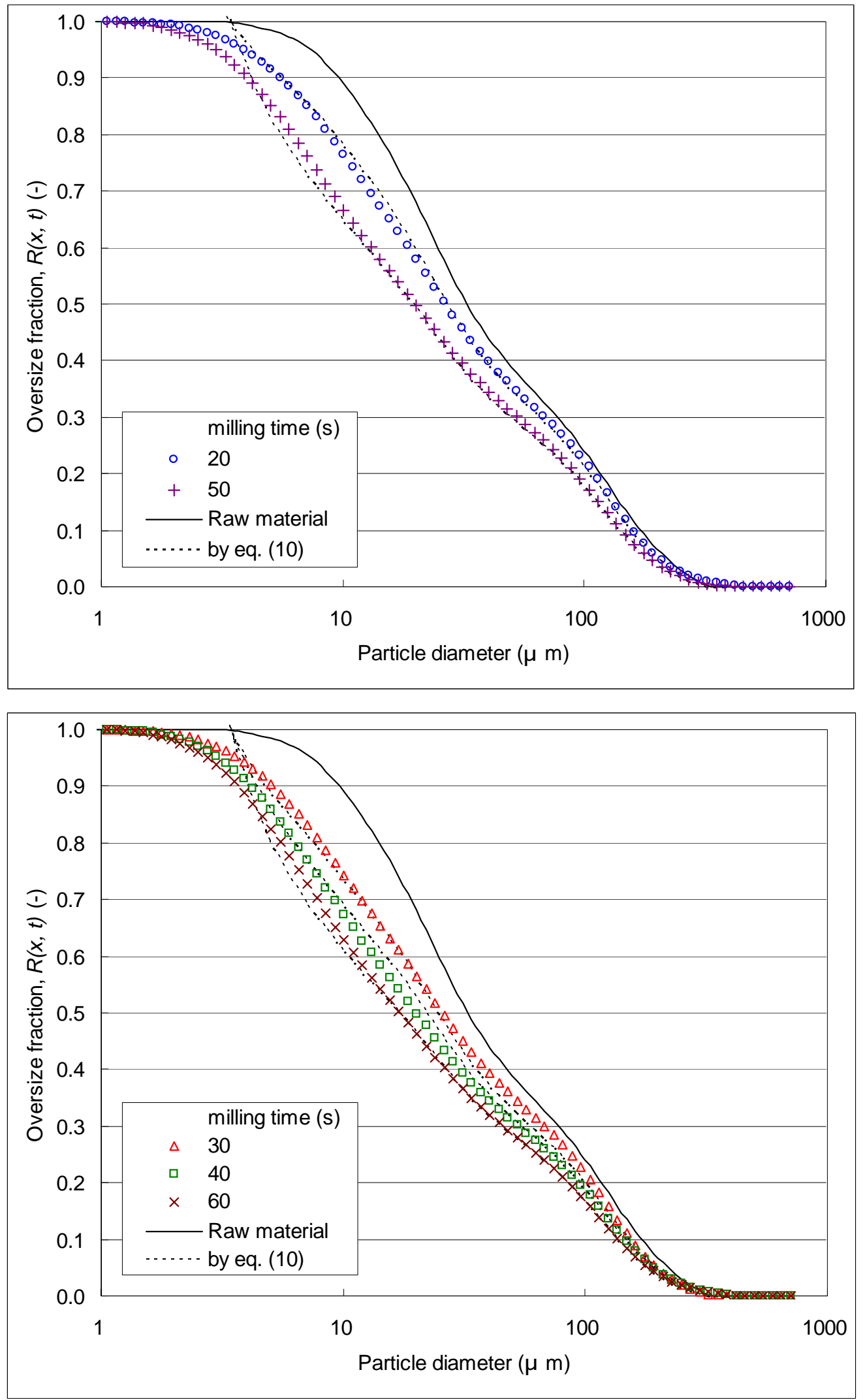

Fig. 2. particle size distributions of raw material and inside samples for Run\#1 


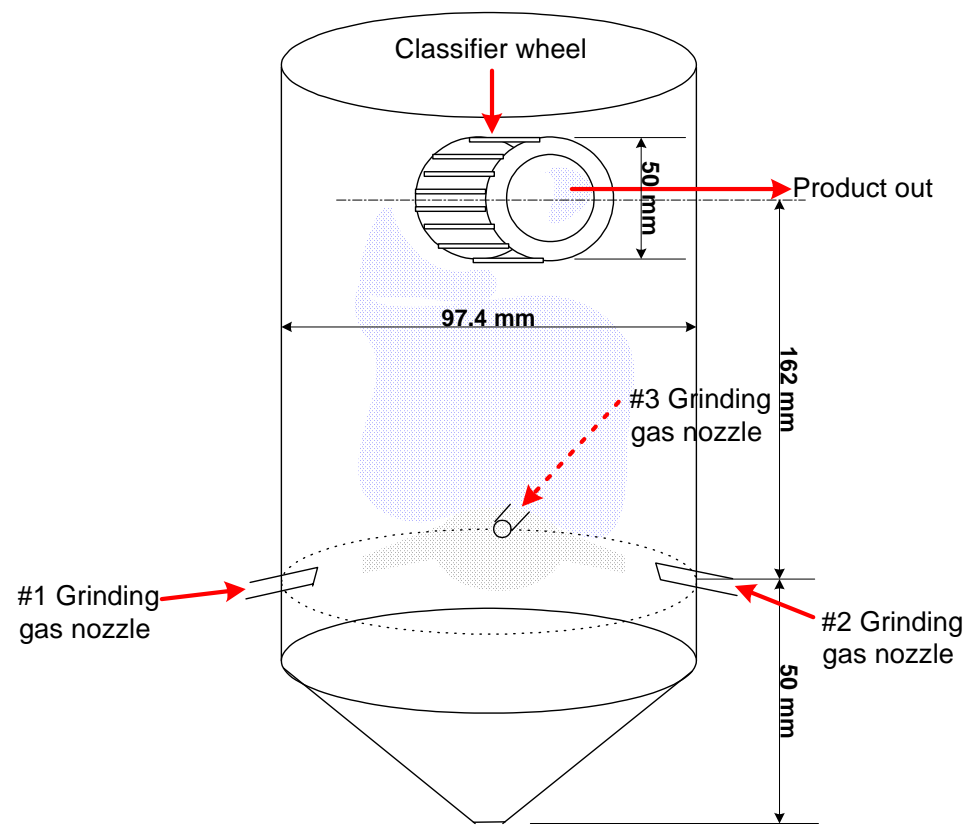

Fig. 3. Schematic illustration of fluidized-bed jet-mill

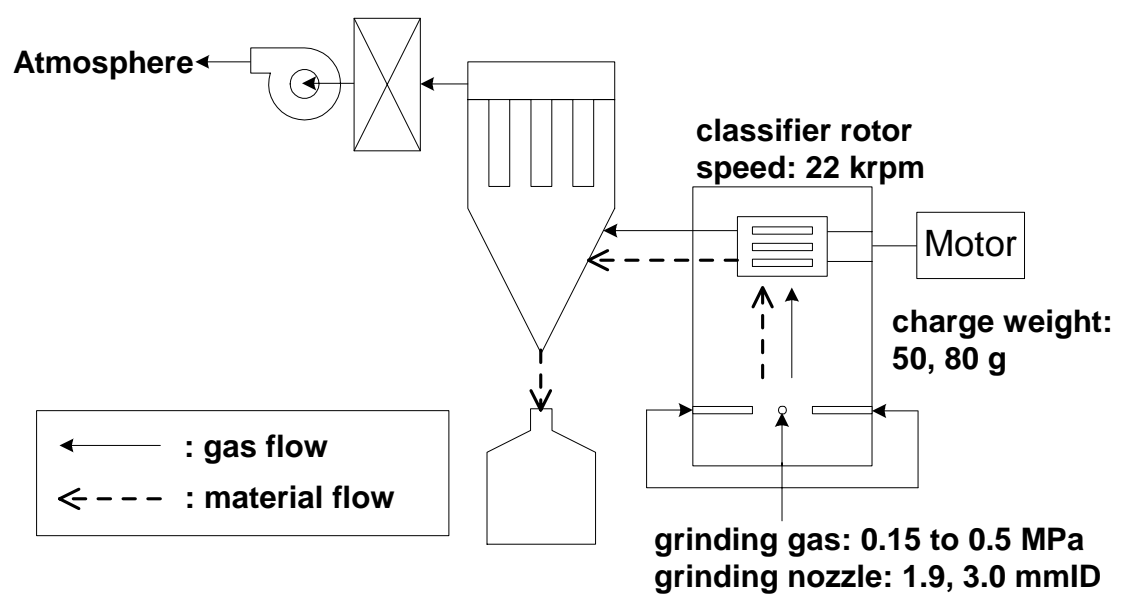

(1)Fluidized-bed jet-mill, (2)Bag filter, (3)Product-recovery pot, (4)HEPA filter, (5)Blower

Fig. 4. Experimental setup for fluidized-bed jet-mill 

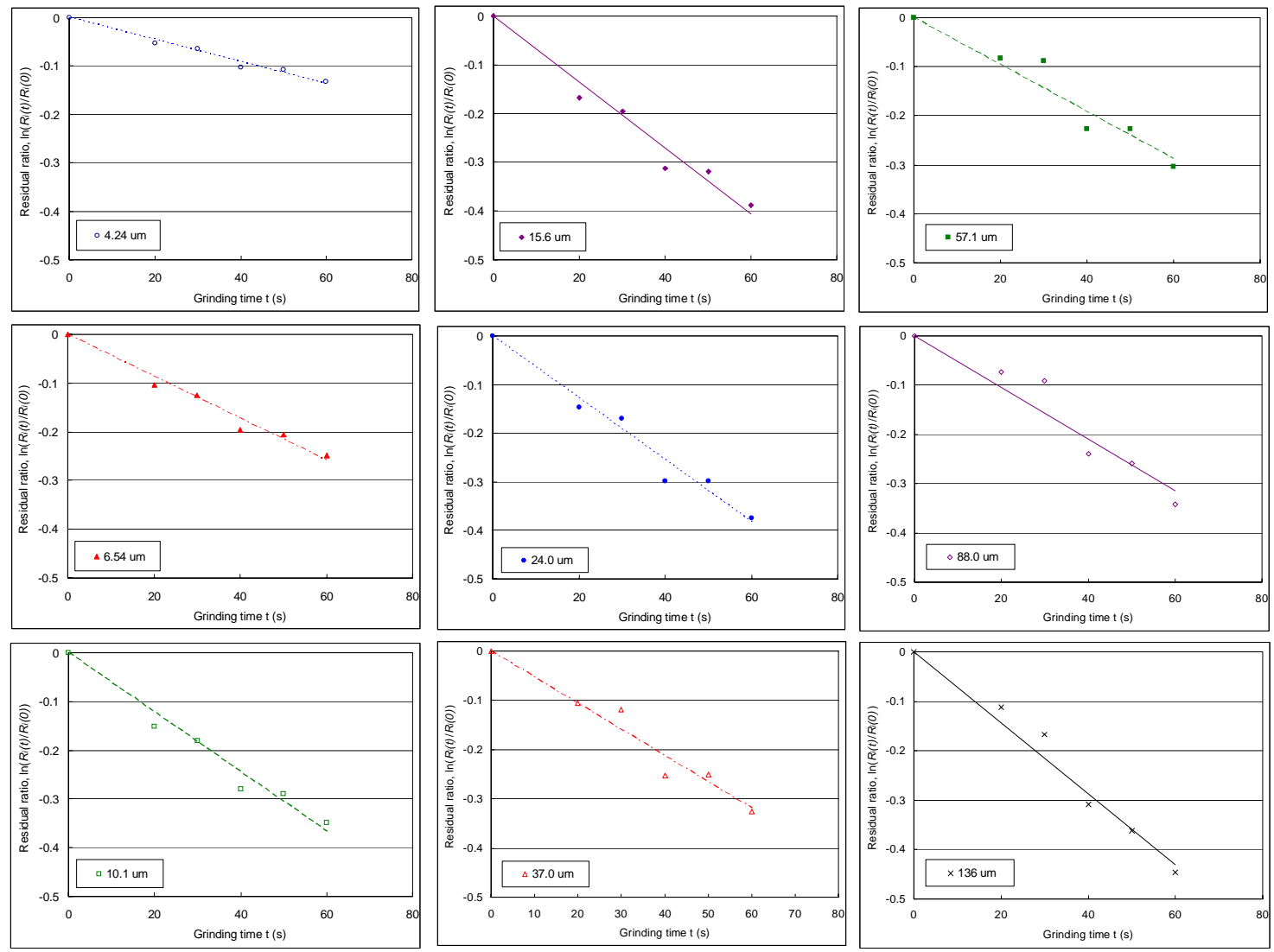

Fig. 5. Data fitting of residual ratio to grinding time by batch grinding 


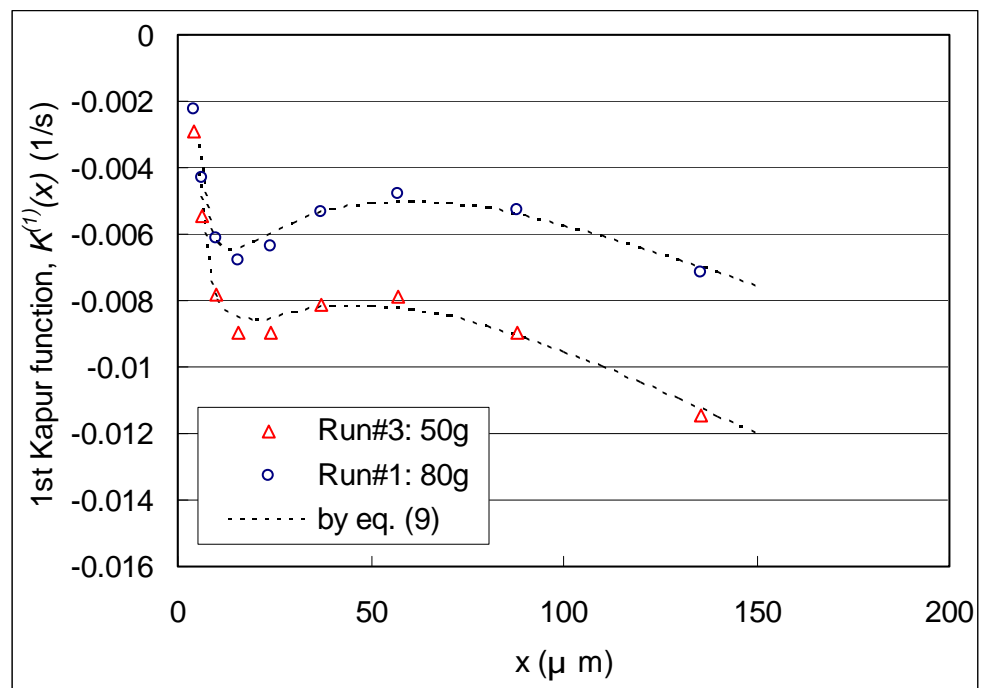

Fig. 6 (a). Effect of charge weight on 1st Kapur function at $0.3 \mathrm{MPa}$ with $1.9 \mathrm{~mm}$-nozzle

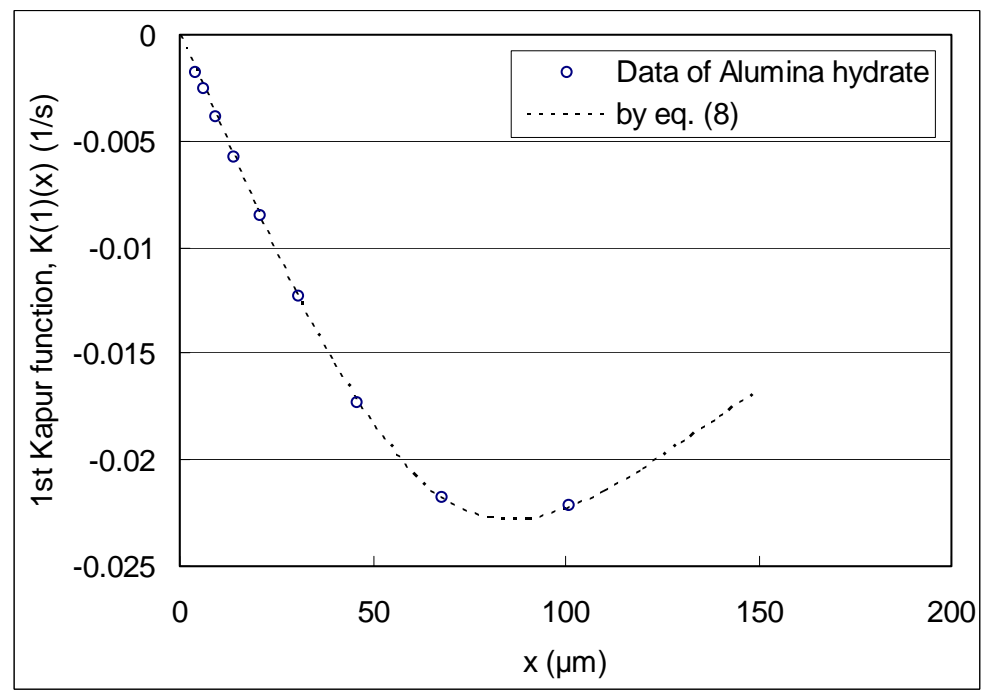

Fig. 6 (b). Variation of 1st Kapur function with particle size for Alumina hydrate (Berthiaux et al., Powder Technol., 78-87, 1999.) 


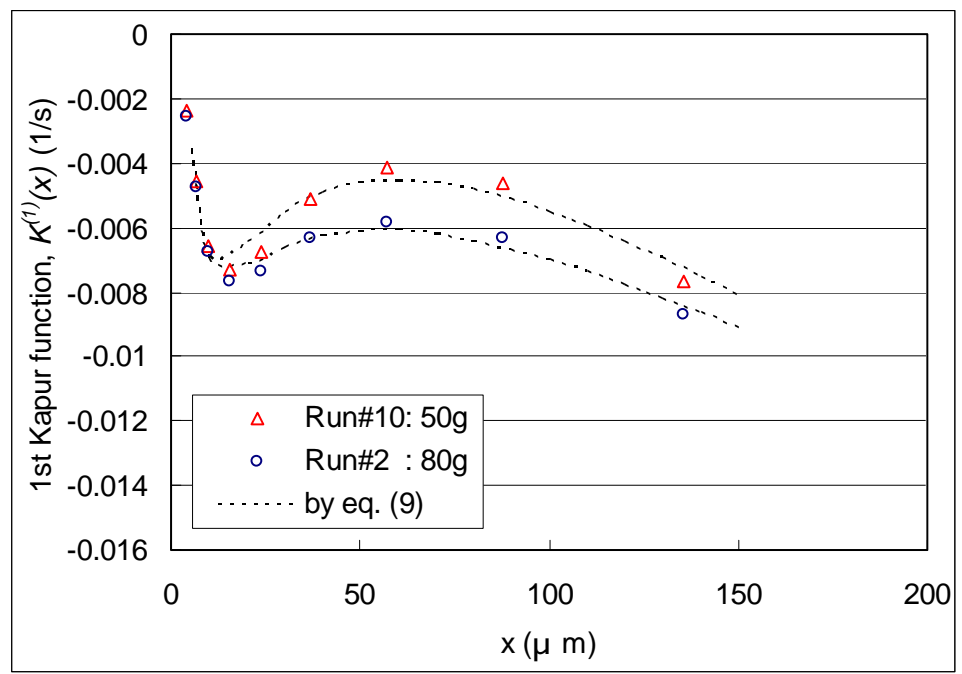

Fig. 7. Effect of charge weight on 1st Kapur function at $0.4 \mathrm{MPa}$ with 1.9 mm-nozzle

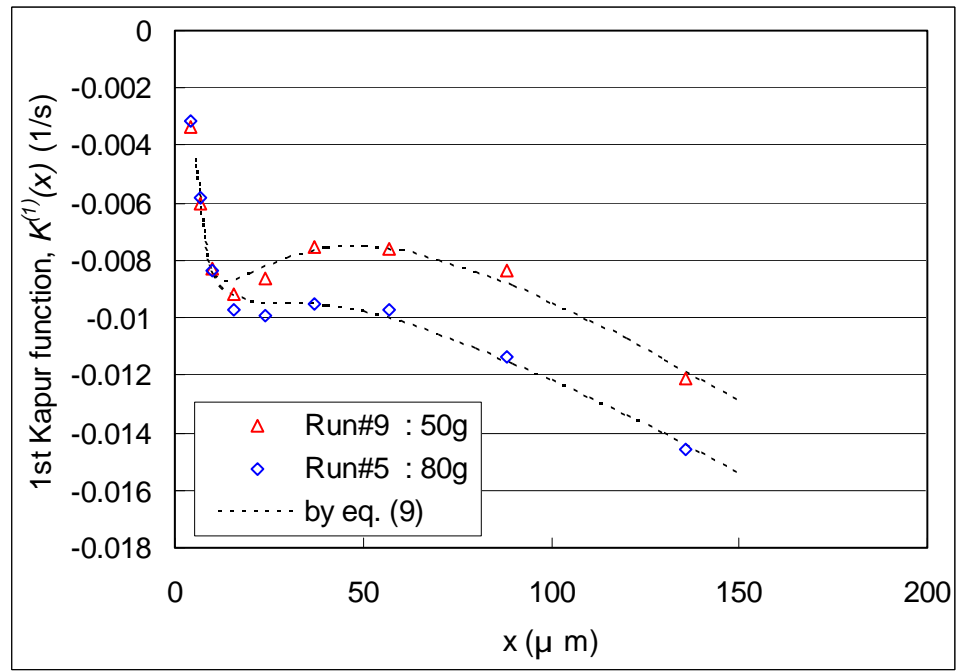

Fig. 8. Effect of charge weight on 1st Kapur function at $0.5 \mathrm{MPa}$ with 1.9 mm-nozzle 


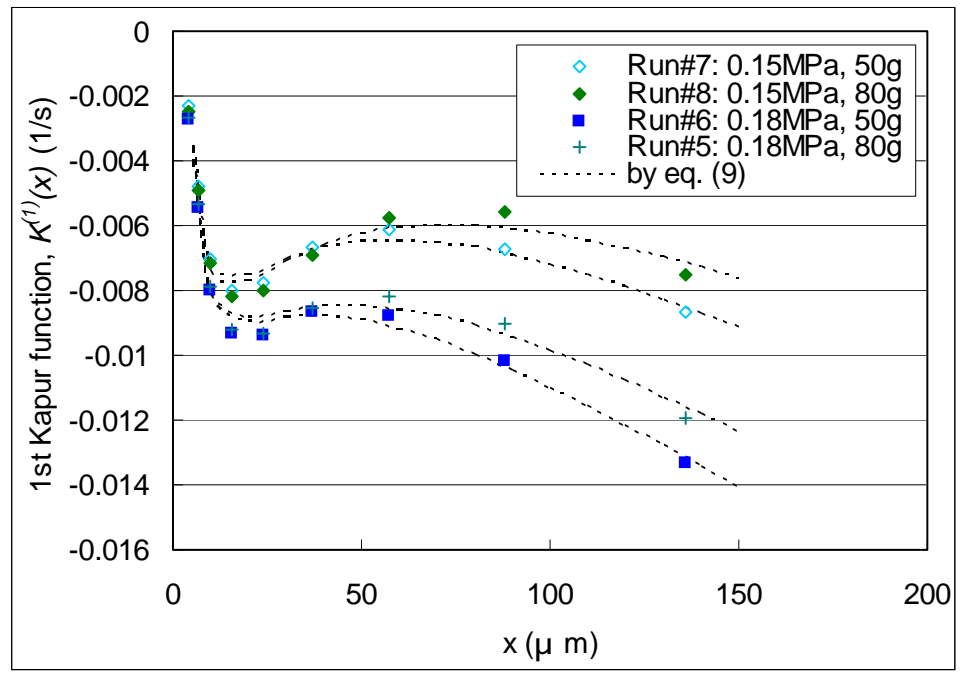

Fig. 9. Effects of charge weight and grinding pressure on 1st Kapur function with $3.0 \mathrm{~mm}$-nozzle

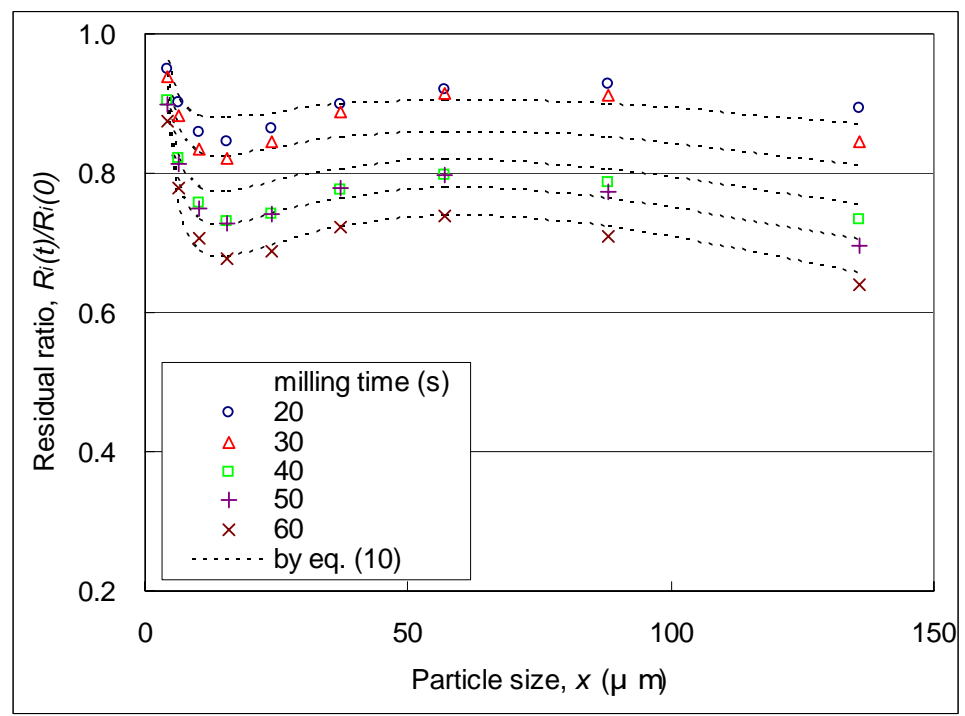

Fig. 10. Fitting of batch grinding data by equation (10) 


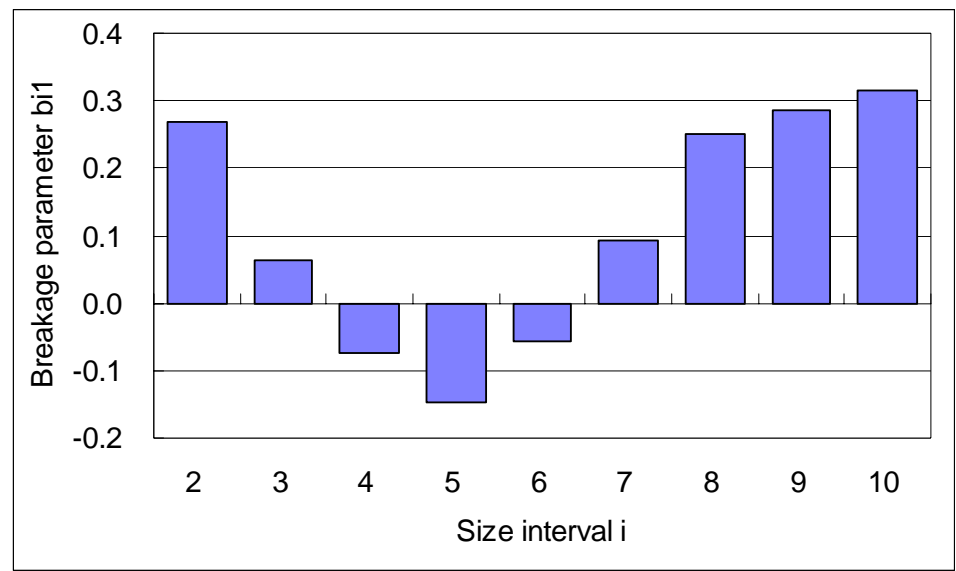

Fig. 11. Mass distribution of fragments produced by breakage of particles of class 1 size 
Table 1

Experimental condition by batch grinding

\begin{tabular}{|c|c|c|c|c|c|}
\hline Run\# & $\begin{array}{c}\text { nozzle dia. } \\
(\mathrm{mm})\end{array}$ & $\begin{array}{c}\text { gas press. } \\
P(\mathrm{MPa})\end{array}$ & $\begin{array}{c}\text { gas flow rate } \\
Q\left(\mathrm{~m}^{3} / \mathrm{min}\right)\end{array}$ & $\begin{array}{c}\text { charge weight } \\
(\mathrm{g})\end{array}$ & $\begin{array}{c}\text { linear gas velocity } \\
\text { at nozzles }(\mathrm{m} / \mathrm{s})\end{array}$ \\
\hline Raw material & - & - & - & - & - \\
\hline 1 & 1.9 & 0.3 & 0.40 & 80 & 784 \\
\hline 2 & 1.9 & 0.4 & 0.51 & 80 & 999 \\
\hline 3 & 1.9 & 0.3 & 0.40 & 50 & 784 \\
\hline 4 & 1.9 & 0.5 & 0.59 & 80 & 1156 \\
\hline 5 & 3.0 & 0.18 & 0.70 & 80 & 550 \\
\hline 6 & 3.0 & 0.18 & 0.70 & 50 & 550 \\
\hline 7 & 3.0 & 0.15 & 0.63 & 50 & 495 \\
\hline 8 & 3.0 & 0.15 & 0.63 & 80 & 495 \\
\hline 9 & 1.9 & 0.5 & 0.59 & 50 & 1156 \\
\hline 10 & 1.9 & 0.4 & 0.51 & 50 & 999 \\
\hline
\end{tabular}

Table 2

Results of curve-fitting for 1st Kapur function

\begin{tabular}{|c|c|c|c|c|c|}
\hline Run\# & \multirow{2}{*}{$R^{2}$ value } & \multicolumn{4}{|c|}{ Coefficients and constant in equation (9) } \\
\cline { 3 - 6 } & & $a$ & $b$ & $c$ & $d$ \\
\hline 1 & 0.956 & $-9.555 \mathrm{E}-04$ & $9.624 \mathrm{E}-03$ & $-3.080 \mathrm{E}-02$ & $2.535 \mathrm{E}-02$ \\
\hline 2 & 0.953 & $-1.027 \mathrm{E}-03$ & $1.033 \mathrm{E}-02$ & $-3.331 \mathrm{E}-02$ & $2.750 \mathrm{E}-02$ \\
\hline 3 & 0.976 & $-1.044 \mathrm{E}-03$ & $1.047 \mathrm{E}-02$ & $-3.433 \mathrm{E}-02$ & $2.832 \mathrm{E}-02$ \\
\hline 4 & 0.987 & $-1.094 \mathrm{E}-03$ & $1.073 \mathrm{E}-02$ & $-3.512 \mathrm{E}-02$ & $2.887 \mathrm{E}-02$ \\
\hline 5 & 0.970 & $-1.086 \mathrm{E}-03$ & $1.097 \mathrm{E}-02$ & $-3.628 \mathrm{E}-02$ & $3.056 \mathrm{E}-02$ \\
\hline 6 & 0.981 & $-1.147 \mathrm{E}-03$ & $1.133 \mathrm{E}-02$ & $-3.693 \mathrm{E}-02$ & $3.083 \mathrm{E}-02$ \\
\hline 7 & 0.964 & $-1.021 \mathrm{E}-03$ & $1.043 \mathrm{E}-02$ & $-3.420 \mathrm{E}-02$ & $2.875 \mathrm{E}-02$ \\
\hline 8 & 0.935 & $-9.949 \mathrm{E}-04$ & $1.044 \mathrm{E}-02$ & $-3.474 \mathrm{E}-02$ & $2.938 \mathrm{E}-02$ \\
\hline 9 & 0.971 & $-1.362 \mathrm{E}-03$ & $1.327 \mathrm{E}-02$ & $-4.154 \mathrm{E}-02$ & $3.348 \mathrm{E}-02$ \\
\hline 10 & 0.910 & $-1.287 \mathrm{E}-03$ & $1.277 \mathrm{E}-02$ & $-3.984 \mathrm{E}-02$ & $3.291 \mathrm{E}-02$ \\
\hline
\end{tabular}

Table 3

Classification of particle size range

\begin{tabular}{|c|c|}
\hline $\begin{array}{c}\text { Particle class } \\
i, j\end{array}$ & $\begin{array}{c}\text { Particle size range } \\
\text { (_m) }\end{array}$ \\
\hline 1 & $>136$ \\
\hline 2 & $88.0-136$ \\
\hline 3 & $57.1-88.0$ \\
\hline 4 & $37.0-57.1$ \\
\hline 5 & $24.0-37.0$ \\
\hline 6 & $15.6-24.0$ \\
\hline 7 & $10.1-15.6$ \\
\hline 8 & $6.54-10.1$ \\
\hline 9 & $4.24-6.54$ \\
\hline 10 & $<4.24$ \\
\hline
\end{tabular}


Table 4

Matrices of $S$ and $B$ calculated

$$
\begin{aligned}
& S=\frac{1}{100}\left[\begin{array}{llllllllll}
0.7162 & 0.5248 & 0.4790 & 0.5314 & 0.6371 & 0.6779 & 0.6106 & 0.4315 & 0.2267 & 0.0000
\end{array}\right] \\
& B=\left[\begin{array}{ccccccccccc} 
& j=1 & 2 & 3 & 4 & 5 & 6 & 7 & 8 & 9 & 10 \\
i=1 & 0 & 0 & 0 & 0 & 0 & 0 & 0 & 0 & 0 & 0 \\
2 & 0.267 & 0 & 0 & 0 & 0 & 0 & 0 & 0 & 0 & 0 \\
3 & 0.064 & 0.087 & 0 & 0 & 0 & 0 & 0 & 0 & 0 & 0 \\
4 & -0.073 & -0.100 & -0.109 & 0 & 0 & 0 & 0 & 0 & 0 & 0 \\
5 & -0.148 & -0.201 & -0.221 & -0.199 & 0 & 0 & 0 & 0 & 0 & 0 \\
6 & -0.057 & -0.078 & -0.085 & -0.077 & -0.064 & 0 & 0 & 0 & 0 & 0 \\
7 & 0.094 & 0.128 & 0.141 & 0.127 & 0.106 & 0.099 & 0 & 0 & 0 & 0 \\
8 & .250 & 0.341 & 0.374 & 0.337 & 0.281 & 0.264 & 0.293 & 0 & 0 & 0 \\
9 & 0.286 & 0.390 & 0.428 & 0.385 & 0.321 & 0.302 & 0.335 & 0.475 & 0 & 0 \\
10 & 0.317 & 0.432 & 0.473 & 0.427 & 0.356 & 0.334 & 0.371 & 0.525 & 1.000 & 1.000
\end{array}\right]
\end{aligned}
$$

